\title{
Challenge of Integrating Entrepreneurial Competencies into Technical College Programs
}

\author{
Abubakar Ibrahim Muhammad, Yusri Bin Kamin, Nur Husna Binti Abd. Wahid
}

\begin{abstract}
For a country to keep abreast of being competitive in global economy technical and vocational education must play a critical role. For long time, technical and vocational education disciplines have been in cache, living graduates unable to connect learned knowledge with real life problems. The emergence of integrating technical education with entrepreneurial competencies in some institutions in Nigeria advocates transformative changes both at the conceptual and technological levels. One of the challenge facing technical education in Nigeria is lack of appropriate entrepreneurial competencies in the content of technical college curriculum. The purpose of the study was to explore the challenge facing the integration of entrepreneurial competencies into the technical college curriculum. This study uses phenomenological research design method was guided by interview protocol, thus the data were qualitatively collected. This research involved ten experts from three technical institutions in Kano state Nigeria based on their educational background, field of teaching and experience in entrepreneurship education. The study found that poor funding, lack of qualified teachers, inappropriate curriculum and negative attitude toward on entrepreneurship education are the main challenges hindering the integration of entrepreneurial competencies into technical college programs in Nigeria. It is recommended that the need for an appropriate entrepreneurial competencies for technical college programs this will facilitate easy and rapid self-employment among the graduates to enable them become novice entrepreneurs for self-reliance. Consequently, 20 per cent of public expenditure should be allocated to bridge the gap in funding education.
\end{abstract}

Index Terms: Entrepreneurial Competencies, Integration, Technical College.

\section{INTRODUCTION}

Technical education is the back bone of youth empowerment for self-reliance in many countries including Nigeria. The system has suffered and continue to suffer with tremendous challenges for decades. It does not fulfil its overall objectives as stated in the National Policy on Education (NPE). The Federal Republic of Nigeria (FRN) stipulated in the NPE that in pursuant of the stated goals of technical education at the technical college level graduates completing technical college programs shall be able to: set up their own business; become self-employed; be able to

Revised Manuscript Received on April 19, 2019.

Abubakar Ibrahim Muhammad, Federal College of Education (Technical), Bichi PMB 3473 Kano Nigeria, and Technical and Engineering Education Department, Universiti Teknologi Malaysia, Johor Bahru 81300, Malaysia.

(Email: i.muhammad@graduate.utm.my, abuhumran@yahoo.com)

Yusri Bin Kamin, Technical and Engineering Education Department, Universiti Teknologi Malaysia, Johor Bahru 81300, Malaysia.

(Email: p-yusri@utm.my)

Nur Husna Binti Abd. Wahid, Technical and Engineering Education Department, Universiti Teknologi Malaysia, Johor Bahru 81300, Malaysia. (Email: husna@utm.my) employ others [1]. However, the situation is not like that as the curriculum is not well design to accommodate aspect of entrepreneurial competencies [2]. The NPE stated that the curriculum of technical education for each trade at technical college level shall consist entrepreneurial competencies [1]. Essentially, every technical course is supposed to have four arms that include cognitive, affective, psychomotor and entrepreneurial arm. In [3] essence, having the first three variables is not enough to sale products but having all these together with entrepreneurship could lead to selfemployment. But unfortunately, with all the importance of integrating entrepreneurial competencies stated above up to this moment the curriculum of technical colleges is not incorporated with entrepreneurial competencies [4]. Consequently, considering the fore going it has been affirmed that nowadays teaching entrepreneurship education to technical education students is an essential pillar in building social responsibility with strong impact on the future economic development of the society [5].

Summarily, the incorporation of entrepreneurial competencies into technical colleges programs in Nigeria is bedeviled with so many challenges which this paper set to identify. In Nigeria there is fallacy among the scholars in terms of connecting technical education with entrepreneurial competencies as curriculum developers in that section misunderstood the two concepts. To them an individual with technical education certificate is not in need of entrepreneurial competencies or training [6]. That is why the curriculum is silent about the entrepreneurial competencies needed by technical college students to help them to start-up a venture on graduation. While the latest requirement of knowledge-based society actually entails technical education students to equip themselves with a broad range of skills, among which is entrepreneurship competencies [7]. Actually, for instance, in the United States of America, research on entrepreneurship in the field of technical and engineering education shows that entrepreneurship programs and courses in technical and engineering education is fast growing over the past two decades [8].

Going by the foregoing discussions on the importance of integrating entrepreneurial competencies into technical college curriculum Onuma [4] suggest that the curricular of technical colleges should be reviewed to integrate entrepreneurial competencies. Furthermore, Almeida [9] du Toit and Gaotlhobogwe [10] emphasized the significance of integrating entrepreneurial competencies to technical education programs. The inclusion of entrepreneurial 
competencies into technical education curriculum would produce creative and innovative students [11]. These students would remain more creative and innovative if the program is well design and implemented which in turn would definitely lead them to self-employment.

\section{PURPOSE OF THE STUDY}

The purpose of this study was to explore the challenge hindering integrating of the entrepreneurial competencies into technical college programs.

\section{RESEARCH QUESTION}

What are the challenge hindering the integration of the entrepreneurial competencies into technical college programs?

\section{METHODOLOGY}

Phenomenological research design method was used in this study. The data was gathered through semi structured interview method, involving ten experts from three technical institutions in Kano state Nigeria namely Institution A (IA), Institution B (IB) and Institution C (IC). These experts were chosen purposively as participants in the research based on their educational background, teaching and learning experience. To get saturated data, three experts were interviewed in IA, three experts were interviewed in IB and four experts were interviewed in IC.

Based on the interview with the participants their perspective has been explored in terms of their view relating the challenges that hinder the integration of entrepreneurial competencies were qualitatively collected. The interview protocol consists of two parts. The first part was the demographic of the participants; while the second part was the main interview question. At the end, the data was inductively transcribed and analyzed through thematic method. In the analysis of qualitative content, the data generated are classified inductively [12].

The interview session consist of asking questions to the interviewees about the challenge of integrating entrepreneurial competencies into technical college programs; and listening carefully to their responses thereby taking note of the important responses. Additionally, to ensure validity and reliability of the instrument for data collection in this study, researchers followed the suggestion of Gibbs (2007) in [12] in which the transcripts were checked to make sure of free clear errors during transcription. Codes (P1, P2, P3, P4, P5, P6, P7, P8, P9 and $\mathrm{P} 10)$ were developed to cross-verify by different researchers and compare the results obtained independently. Deviation in the definition of the codes has been taken care to make sure there is no change in the meaning of the codes during the coding process. Finally, triangulation of various sources of data information by examining the evidence from the sources and using it to construct a coherent justification for the themes.

\section{FINDINGS OF THE RESEARCH}

The findings of this study were categorized according to the responses of the participants based on the interview questions. Views of the participants were recorded and identified under four main key themes in the study concerning the challenges of integrating entrepreneurial competencies into technical college programs in Nigeria as shown in table 1. The participants have similar characteristics of being technical teachers with experience in entrepreneurial competencies.

Table 1: Summary of the Participants' Responses

\begin{tabular}{|l|l|l|}
\hline Themes & Participants & Percentage \\
\hline$\cdot$ Funding & $\begin{array}{l}\text { P1, P2, P3, P4, P5, P6, P7, } \\
\text { P8, P9 and P10 }\end{array}$ & 100 \\
\hline $\begin{array}{l}\bullet \text { Qualified } \\
\text { teachers }\end{array}$ & $\begin{array}{l}\text { P1, P2, P3, P4, P5, P6, P7, } \\
\text { P8, P9 and P10 }\end{array}$ & 100 \\
\hline $\begin{array}{l}\cdot \text { Curriculum } \\
\text { P1, P2, P3, P4, P5, P6, P7, } \\
\text { P8, P9 and P10 }\end{array}$ & 100 \\
\hline $\begin{array}{l}\cdot \text { Attitudinal } \\
\text { change }\end{array}$ & $\begin{array}{l}\text { P1, P2,P3, P4, P5, P6,P8 and } \\
\text { P10 }\end{array}$ & 80 \\
\hline
\end{tabular}

The findings of the study were summarized based on the research question (What are the challenge hindering the integration of entrepreneurial competencies into technical college programs?) thus, the themes identified in this study including: lack of funding, inadequacy of qualified teachers, poor attitude and inappropriate curriculum.

\section{Summary of Typical Responses of the Participants}

In the issue of the challenge about funding this theme was extracted from the responses of the participants. Some of the participants' responses are as follows:

P1 “......... to my own understanding lack of adequate funding is one of the greatest issue that will face the entrepreneurial training to technical colleges."

P2 “.... Lack of funding”

P3 "Lack of adequate finance"

P5 “.... Insufficient allocation of funds"

The responses continues:

P7 “.... Lack of financial support from the government”

P8 ".... Inadequate mobilization funds"

P10 "........ poor funding and manpower"

Second theme extracted from the interview was the problem of lack of adequate qualified teachers. Some of the responses were as follows:

P1 “...... another problem I am anticipating is the lack of qualified entrepreneurial teacher in the colleges".

P3 “....... Qualified entrepreneur teachers at technical college level"

P4 "..... Involvement of experts in the field"

P5 "..... You see another problem is to hinder the integration is lack of qualified teachers in the technical colleges"

The responses continues

P6 "...... inadequate experienced professionals in the field"

P7 “... hmm lack of qualified entrepreneurship teachers is a big challenge ..."

Consequently, the participants mentioned among others the curriculum issue as a challenge that would hinder the integration of entrepreneurial competencies into technical college programs in Nigeria. Some of the typical responses

Published By: 
are as follows:

$\mathrm{P} 2$ ".....hmm, in fact inappropriate curriculum is a big hindrance ..."

P3 “.... Effective Curriculum at technical level”

P4 "....No sound curriculum aimed at producing entrepreneurs"

P5 “...... Problems of curriculum”

Furthermore, the responses continued

P6 ".... stakeholders in education to mount infusing entrepreneurial competitions in to its curriculum."

P7 “.... Ah! Yes, implementation process of the curriculum to be done"

P8 “.... hmm... Yes, I think it is important to have an appropriate curriculum for the technical college programs."

The final theme extracted from the interview was the issue of attitude among the stake holders and the general populace about the entrepreneurial competencies. The responses were as follows:

P1 “...... we also need to look at the attitude of our people towards the integration of the entrepreneurial education in technical colleges". He continues “........ You see some of the stake holder are in the view that there is no need for entrepreneurial education in technical education since the latter ensures skills acquisition to the students."

P2 “...... lack of proper awareness among the populace”

P3 “....... Attitudinal change”

P4 “..... Lack of awareness/intent”

The responses continued

P5 “.... Lack of interest"

P6 “.... Due regards and attention”

P8 “... Lack of good planning of the program”

P10 “.... public none challenge attitude.”

All the participants (P1, P2, P3, P4, P5, P6, P7, P8, $\mathrm{P} 9$ and $\mathrm{P} 10)$ unanimously agreed that "one of the challenge facing the integration of entrepreneurial competencies into technical college curriculum is the lack of appropriate funding from the government." Therefore lack of adequate funding for technical college programs has to be tackled appropriately in order to build a strong entrepreneurial training among the technical college students that would enable them to become prospective novice entrepreneurs that would help in bursting the economy of the country by enhancing poverty alleviation among the teaming youths. Consequently, allocation of 15 to 20 per cent of annual budgetary to education as recommended by UNESCO will help to curtail these challenges.

The study also explored that lack of qualified teachers is one of the vital challenges confronting the integration of entrepreneurial program into technical colleges. Overall participants, (P1, P2, P3, P4, P5, P6, P7, P8, P9 and P10) believed that "inadequate experienced professional in the field and lack of involvement of experts in the field is aggravating the integration of the entrepreneurial education into the technical colleges." Therefore it is highly important to employ qualified entrepreneurial teachers for the success of the program.

Another important challenge of integrating of entrepreneurial competencies into technical programs is the issue of curriculum the participants (P1, P2, P3, P4, P5, P6, $\mathrm{P} 7, \mathrm{P} 8, \mathrm{P} 9$ and P10) unanimously agreed with the issue of having an appropriate curriculum that contain entrepreneurial competencies for the training of technical college students. "Effective curriculum at technical level that will contain entrepreneurial competencies are essential. Because at moment there is no sound curriculum aimed at producing entrepreneurs." Therefore the issue of curriculum is sensitive it has to be handle urgently by the National Board for Technical Education (NBTE) and all the stakeholders in education to infuse the entrepreneurial competencies into the curriculum. Another important segment is the implementation process of the curriculum this should also be taken into consideration." It is important to note that an appropriate entrepreneurial competencies model will make things better for the technical college programs.

Attitudinal change, according to most of the participants (P1, P2, P3, P4, P5, P6, P8 and P10) "one of the problem facing integration of entrepreneurial competencies into technical college programs is lack of proper awareness among the technical education graduates. In the same vein lack of interest among the stakeholders may hinder the inculcation of entrepreneurial competencies into technical college programs. This lack of awareness give birth to misconception between technical skills and entrepreneurial competencies. Because most of the technical education stakeholders believed that for technical college students no need to teach them entrepreneur competencies since they already have the technical skills need for employment." Therefore it is important to address this issue of misconception among the stakeholders. This study contributes for the clarification of this misconception.

\section{DISCUSSION}

The result shows that participants unanimously agreed that lack of funding from the government hinders the integration of entrepreneurial competencies into technical college programs in Nigeria. This finding is in line with findings of Agbonlahor [13] that poor funding is one of the major challenge facing entrepreneurship education in Nigerian universities. Accordingly, Ajagbe et al. [14] found that due to the lack of funds in teaching entrepreneurial education in secondary schools, the schools have shortage of equipment, teaching materials and laborites. Ubong [6] also lamented that funding is a critical challenge in the implementation of entrepreneurship education in tertiary institutions in Nigeria. According to Akpochafo and Alika [11] research has shown that there are inadequate facilities and effective teaching and learning of entrepreneurship education in Nigerian institutions. Therefore, there is a need for the authority concern to provide enough funds at least 15 to 20 per cent of the annual national budgetary as recommended by UNESCO [15] for the proposed integration of entrepreneurial competencies into technical college programs to achieve the national policy on education for prosperous economic growth in the country. Consequently, this poor or lack of funding lead to the second issue at stake that is lack of qualified teacher 
All the participant unanimously agreed that lack of qualified entrepreneurship teachers is a great challenge to the integration of entrepreneurship into technical college programs. This is in agreement with the recommendation of Agbolahor [13], and Ubong [6] even at the tertiary level apart from the lack of qualified teachers institutions are left to demine who will be the teacher. Consequently, lack of qualified teachers is a great challenge towards integrating entrepreneurial competencies into technical college programs [16] lamented the situation as the shortage of professional teachers to teach the subject in the schools. According to Hammad [17] one of the serious challenge for entrepreneurship education in developing countries is the difficulty in recruiting and hiring of qualified teachers who teaches the entrepreneurial competences. Therefore, since qualified teachers are the backbone of teaching and learning activities, so it is important to recruits qualified teachers for a successful integrating entrepreneurial competencies into technical college programs.

The results also described the scenario that could face the integration of entrepreneurial competencies into technical college programs is the issue of curriculum. All the participants were opined that curriculum is one of the major challenge of the integration. This is in agreement with Okuta and Dawha [18] who observed that lack of practical based entrepreneurial curriculum is a major obstacle in the integration of entrepreneurship into technical college programs. Therefore it is worthy to mention that a curriculum with entrepreneurial competencies for technical college programs is highly required in this material time.

The results also shows that there is a lack of awareness among most of the technical education graduates about entrepreneurship education. Most of the participants opined that this scenario has to be tackled in good time to give way for the integration of the entrepreneurial competencies into technical college programs. This is in accordance with the assertion of Unachuku [19] majority of Nigerians have utopian ideas about entrepreneurship education. Therefore an appropriate entrepreneurial competencies model helps in bringing the gap in understanding the importance of entrepreneurial competencies for technical college students.

Conclusively, the study found that poor funding, lack of qualified teachers, inappropriate curriculum and negative attitude toward integrating entrepreneurial competencies into technical college programs are the main obstacles for the integration. No such study was done in Nigerian content in particular at technical college level. Therefore it is recommended to take urgent action in tackling the situation by having an appropriate entrepreneurial competencies model for technical college programs in Nigeria.

\section{RECOMMENDATIONS}

An appropriate entrepreneurial competencies will make things better for the technical college programs in such a way that it enhances effective teaching and learning activities. Therefore, there is need for adequate provision of entrepreneurial courses in the technical colleges in order to enhance economic development in the country. Furthermore, the curriculum of technical colleges is capable of training students to acquire the basic knowledge of technical and vocational education but it lacks the entrepreneurial aspect. Consequently, it is recommended for the need of an appropriate embedding of entrepreneurial competencies into technical college programs to facilitate easy and rapidly develop the graduates to enable them become novice entrepreneurs for self-reliance. Consequently, 20 per cent of public expenditure should be allocated to bridge the gap in funding education.

\section{CONCLUSION}

The introduction of entrepreneurial competencies to technical college students will boost the economy through Small and Medium Enterprises (SMEs) development in Nigeria as it provide business opportunity for selfemployment and reduces the over dependence on government for employment. There is a need to have an appropriate curriculum and effective implementation of the program by the stake holders. Carefully looking at the responses it could be understood that there are numerous challenges facing the integration of entrepreneurial competencies into technical college programs. These challenges include, poor funding, lack of qualified entrepreneurship teacher, inappropriate curriculum and peoples' attitude towards the integration process. These challenges if not appropriately handled by the stakeholders it hinders the so much desire for the integration of entrepreneurial competencies into technical colleges programs for the betterment of our teaming youths..

\section{ACKNOWLEDGMENT}

The Authors thanks the ten experts from three technical institutions in Kano state Nigeria involved in this research. Also A. I. Muhammad thanks Universiti Teknologi Malaysia for granting International Doctoral Fellowship.

\section{REFERENCES}

1. Federal Republic of Nigeria, "National policy on education." Nigerian Educational Reseach and Development Council, Lagos, p. 47, 2013.

2. A. Idris, "A conceptual model on the implementation of technical and vocational education in Nigeria," Universiti Teknologi Malaysia, 2013.

3. A. Yulastri, H. Hidayat, - Ganefri, F. Edya, and S. Islami, "Learning outcomes with the application of Product Based entrepreneurship module in vocational higher education," J. Pendidik. Vokasi, vol. 8, no. 2, pp. 120 $131,2018$.

4. N. Onuma, "Rationale for students preparation and entrepreneurship education in the face of global economic crisis in Nigeria," J. Educ. Pract., vol. 7, no. 12, pp. 200-204, 2016.

5. F. Almeida, "Experience with entrepreneurship learning using serious games," Cypriot J. Educ. Sci., vol. 12, no. 69-80, 2017.

6. B. Ubong, "Entrepreneurship education in Nigeria: issues, challenges, and strategies," Niger. J. Bus. Educ., vol. 4, no. 1, pp. 11-22, 2017.

7. L. Ortiz-Medina, E. Fernández-Ahumada, P. Lara-Vélez, A. Garrido-Varo, D. Pérez-Marín, and J. E. GuerreroGinel, "Assessing an entrepreneurship education project in engineering studies by means of participatory 
techniques," Adv. Eng. Educ., vol. 4, no. 2, pp. 1-30, 2014.

8. M. Besterfield-sacre, S. Zappe, and K. Shartrand, Angela $\&$ Hochsterdt, "Faculty and student perceptions of the content of entrepreneurship courses in engineering education," Adv. Eng. Educ., no. Winter 2016, pp. 1-27, 2016.

9. F. Almeida, "Integration of Erasmus + Students in," Int. J. Teaching, Educ. Learn., vol. 2, no. 3, pp. 101-119, 2018.

10. A. du Toit and M. Gaotlhobogwe, "A Neglected opportunity: Entrepreneurship education in the lower high school curricula for technology in South Africa and Botswana," African J. Res. Math. Sci. Technol. Educ., vol. 22, no. 1, pp. 37-47, 2018.

11. G. O. Akpochafo and I. H. Alika, "Perceived impact of entrepreneurship education on career development among undergraduates in South-South universities in Nigeria: Implication for counselling," J. Educ. Learn., vol. 7, no. 3, p. 102, 2018.

12. J. W. Creswell, Research Design: Qualitative, quantitative, and mixed methods approaches, 4th ed. California: SAGE, 2014.

13. A. A. Agbonlahor, "Challenges of entrepreneurial education in Nigerian universities: towards a repositioning for impact," J. Educ. Soc. Res., vol. 6, no. 1, pp. 208-214, 2016.

14. N. M. Ajagbe, M. A., Kelechi, A. N., Kimuli, S. N. L. \& Cho, "Problems and visions of entrepreneurship education in post primary schools," Int. J. Econ. Commer. Manag. United Kingdom, vol. IV, no. 7, pp. 633-650, 2016.

15. UNESCO, "World Education Forum 2015: Final Report," Paris, 2015.

16. N. Ementa, "Curriculum implementation of entrepreneurial subjects at the senior secondary school: A case for entrepreneurship education at the senior secondary school in Nigeria .," Unizik Orient J. Educ., vol. 7, no. 1, pp. 165-170, 2013.

17. D. B. Hammad, "Current State of entrepreneurship education towards breeding entrepreneurial attitudes among vocational and technical students in colleges of education," Eur. J. Bus. Manag., vol. 10, no. 32, pp. 6874, 2018.

18. S. Okuta and J. M. Dawha, "Challenges of automobile technology in entrepreneurship development," Int. Lett. Soc. Humanist. Sci., vol. 32, pp. 166-174, 2014.

19. G. O. Unachukwu, "Issues and Challenges in the development of entrepreneurship education in Nigeria," african Res. Rev. An Int. Multi-Displinary J., vol. 3, no. 5, pp. 213-226, 2009.

\section{AUTHORS PROFILE}

Abubakar Ibrahim Muhammad is a $\mathrm{PhD}$ in technica and vocational education candidate at the Universiti Teknologi Malaysia with Nigeria certificate of Education (NCE), B. Tech Industrial \& Tech Ed, and MSc. Advanced Materials. Working with Federal College of Education (Technical) Bichi, Nigeria from 2008 to Date as lecturer in Metalwork Technology Department. Assistant Education Officer (AEO) with Kano State Science and Technical Schools Board, between 1994 and 2008. Now as a postgraduate student, he is developing a plethora of excellent experience in scientific research and innovation, conducting an excellent research, and how to sell the new innovation in the world market for the benefit of humanity. In addition he is scrupulous and a career driving with determined approach to meeting targets and team organization. His research interests focus on the entrepreneurial competencies, and technical skills of technical college students.

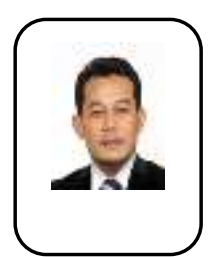

Dr. Yusri Kamin is currently associate professor and as a Director, Department of Technical and Engineering Education Department, School of Education, Faculty of Social Sciences and Humanities, Universiti Teknologi Malaysia. He obtained Bachelor of Technology with Education (Mechanical Engineering) and a Master of Education with Specialization in Technical and Vocational Education) from Universiti Teknologi Malaysia and $\mathrm{PhD}$ (Technical and Vocational Education) from La Trobe University, Melbourne Australia. Among the positions that he held were Director, Head of Department Technical and Engineering Education, and Academic Manager for External Program. He actively involved in conducting research on Developing Model of Preparing Mechanical Program at College Vocational In Malaysia, students preparedness for the workplace in mechanical, workbased learning, employability skill, generic green skill and scenario-based learning. In addition he has written numerous papers and presented at national and international conferences and seminar. Yusri is also a reviewer for the Journal of Asian Academic Society for Vocational Education and Training (JAVET), Journal for Technical and Vocational Education Malaysia, and panel of assessor for Malaysian Qualifications Agency (MQA). At present, he is the president of the Association of Technical and Vocational Education Malaysia.

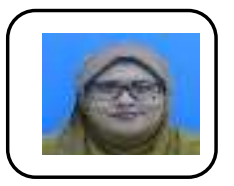

Dr. Nur Husna Abd, Wahid is a senior lecturer in the department of Technical and Engineering Education UTM where she has been a faculty member since 2006. She completed her Ph.D. at Pennsylvania State University in Workforce Education \& Development in 2016. She graduated from University Putra Malaysia (previously known as Malaysian Agriculture University) in 2005 with a Bachelor Degree in Science majoring in Microbiology. In 2010 she completed her Master's Degree in Technical and Vocational Education (agriculture education) from the same University. Her research interests are in the area of agricultural education, technical and vocational and training, teacher preparation, and global teacher competencies. Recently her research explores how diversity in ethnicity, culture, language, and socioeconomic class impact teaching preparedness in technical and vocational education. Her international/global learning experience includes her involvement as the Global Teach Agriculture Initiative Visiting Scholar (2013-2016) at the Department of Agricultural Economics, Sociology, and Education, Penn State 